\title{
Precocious puberty in a patient with Oculo-Auriculo-Verebral spectrum (OAVS)
}

\author{
Pubertà precoce in una paziente con "Oculo-Auriculo-Vetrebral spectrum" (OAVS)
}

\author{
A. Berio, ${ }^{1}$ G. Garlaschi, ${ }^{2}$ A. Piazzi ${ }^{1}$
}

Key words: Oculo- auriculo- vertebral spectrum. Precocious puberty. Neural crest cells.

\begin{abstract}
The authors report on the first case of OAVS (Oculo-AuriculoVertebral-Spectrum), with hemifacial microsomy, hydrocephalus, pubertas precox, thelarche at 4 years of age, vaginal bleeding at 5 years, and left ovary of adult type on echography (right ovary initially not visualized). FISH and CGH-ARRAYS methods were negative. By GnRH therapy the delay of onset puberty was obtained.

The authors ascribe facial and ovary asymmetry to a derangement of blastogenesis, during which axial right-left structures begin the develop with consequent migration or interation with surrounding tissues of neural crest cells and alteration of diencephalic pituitary systems.
\end{abstract}

\section{Riassunto}

Gli autori riportano il primo caso della letteratura di OAVS (OculoAuriculo-Vertebral-Spectrum) con asimmetria facciale, idrocefalo e pubertà precoce, con telarca insorto $\mathrm{a} 4 \mathrm{anni}$, perdite ematiche vaginali a 5 anni ed ovaio sn di tipo adulto, mentre il destro non era inizialmente visualizzato e negativi erano FISH e ARRAYS - CGH.

Attribuiscono l'asimmetria facciale ed ovarica nella bambina ad un disturbo nella blastogenesi, epoca in cui si determinano gli assi corporei destro-sinistro, con successiva anomalia nella migrazione ed interazione delle cellule delle creste neurali con i tessuti ed in particolare con l'ipofisi ed il diencefalo.

\footnotetext{
Dipartimento DINOGMI Università di Genova

2 Dipartimento DISSAL Università di Genova
}

Indirizzo per la corrispondenza (Corresponding author): Prof. A. Berio, Cattedra di Pediatria, Università di Genova,

Largo G. Gaslini 5, 16145 Genova.

Tel +390105636248 . Fax +390103538265

e-mail: agostinoberio@ospedale-gaslini.ge.it
Segnalano i risultati positivi ottenuti sul rallentamento della pubertà mediante preparati a base di Gn RH.

Oculo-auriculo-vertebral spectrum (OAVS) is relatively common condition, involving the structures derived from the branchial arches, but also other organs ${ }^{1}$ We report on the first case of OAVS with precocious puberty.

Family history of the patient, a female, included an aunt of her grandmother with right eye proptosis and microphthalmia, her mother with hearing loss, a brother with right hemifacial microsomia and right eye slight than left.

The mother showed precocious cessation of menstruations (at 35 years of age).

The patient was born by caesarean section, birth weight was 3150 gr, head circumference $38 \mathrm{~cm}$. The baby presented respiratory distress, bilateral pes talo-valgus, feeding difficulties in the first months of life delayed developmental milestones, and frequent otitis.

At 1 years 7 months of life, physical examination showed a female (Fig. 1) in the $75^{\text {th }}$ percentile for height and in the $90^{\text {th }}$ percentile for weight (Italian growth charts). Frontal bossing, right eye microphthalmia with eyelid ptosis and strabismus were present. Palpebral fissures showed slight antimongoloid slant; eye movements were normal bilaterally. The face was asymmetric, with hemifacial microsomia, the chin was receding; mild malar hypoplasia, and the right ear set at a lower level than the left one were present. Ears presented bilaterally simple, with hypoplastic lobules, and were low set (Fig.2). Nasal root was flat and nasal pyramid was downturned. Malocclusion due to mandibular asymmetry, macrostomia, overjet and difficulties in chewing and swallowing were present. Teeth were small with some enamel dysplasias. The voice was nasal and rhinopharingoscopy showed a lateral fissure between pharyngeal velum and posterior pharyngeal wall, during voice emission, with velo-pharyngeal insufficiency. Perceptive hearing was diminished on the right side.

The patient showed hypotonia, brachyphalangy of thumbs, dorsal lordosis and subsequently dorso-lumbar scoliosis, and bilateral pes 


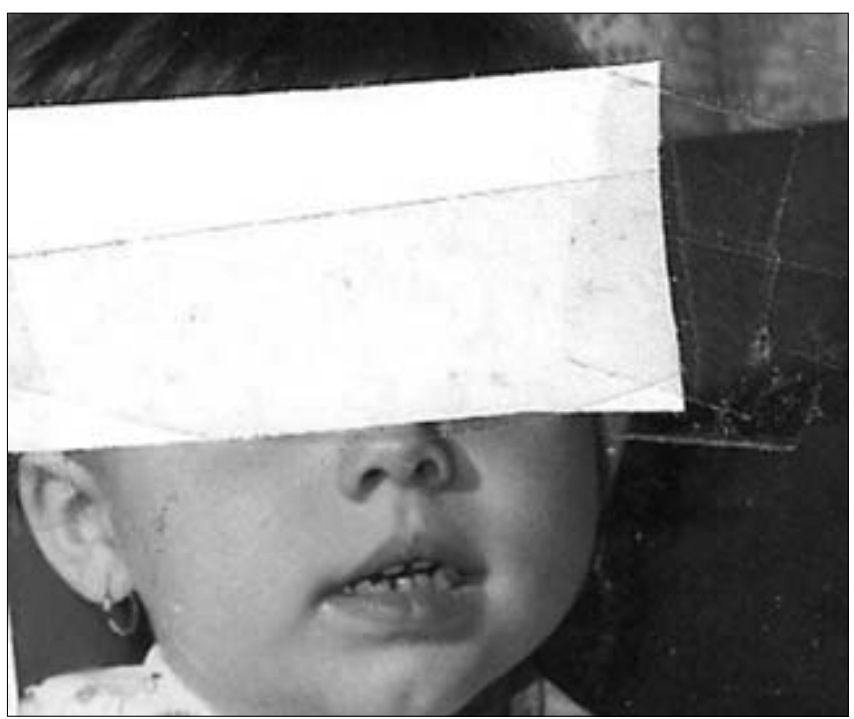

Figure 1.

The "proposita" aged 1 year, 7 months.

Hemifacial microsomia, frontal bossing, malar hypoplasia, right eyelid ptosis, right ear at lower level than left

talo-valgus. She had mild gait ataxia. Normal were routine laboratory tests, ions and DHEAS in serum.

Bone age was 2 years 6 months (+11 months compared to chronological age). Radiological examination of the skull showed frontal bossing with sclerotic cranial base (axial view), asymmetry between right and left temporo-mandibular articular fossae, the right being low-set, asymmetric zygomatic arches, hypoplastic right maxilla, and retrognatie mandible. Brain CT (Fig.3) and successively MRI demonstrated slight cerebral cortical atrophy with hydrocephalus, enlarged cerebral ventricles and subarachnoid spaces. Spine radiology showed L5 bilateral isthmic spondylolisis with sclerosis and spondylolisthesis of the fifth lumbar vertebra on the sacral bone with dorsal scoliosis (at 15 years of age).

The patient presented mild mental retardation. Oculo-AuriculoVertebral-Spectrum (OAVS) was diagnosed.

At 4 years 6 months of age, the patient showed bilateral telarche, weight was $21.800 \mathrm{~g}\left(97^{\circ} \mathrm{P}\right)$, height $106.5 \mathrm{~cm}\left(75^{\circ} \mathrm{P}\right)$.

Bone age was advanced by 4 years. LH, FSH, estradiol are reported in table1. After $\mathrm{GnRH}$, LH peak was 75.9 (after $20 \mathrm{~min}$.), more elevated than FSH peak (20mIU after 20 min.). This response was of pubertal type.

Pelvis echography showed normal uterus but the right ovary could not be visualized and the left ovary was of adult type and volume $(>2 \mathrm{ml}$ ) with follicles smaller than $1 \mathrm{~cm}$. Ecographic control after 6 months showed puberal uterus $(4.5 \mathrm{~cm})$, left ovary of adult type, not visualizable right ovary. The patient presented vaginal bleeding. At 5 years of age, she showed clinical signs of precocious puberty, with breast growth, pubic hair, advanced bone age, LH and FSH values and their peak after GnRH stimulation were typical of puberty (Table 1). Precocious puberty due to hypothalamic-pituitary dysfunction was diagnosed in OAVS.

Karyotype was normal (46, xy) FISH and ARRAY - CGH and Gbanded karyotype were normal.

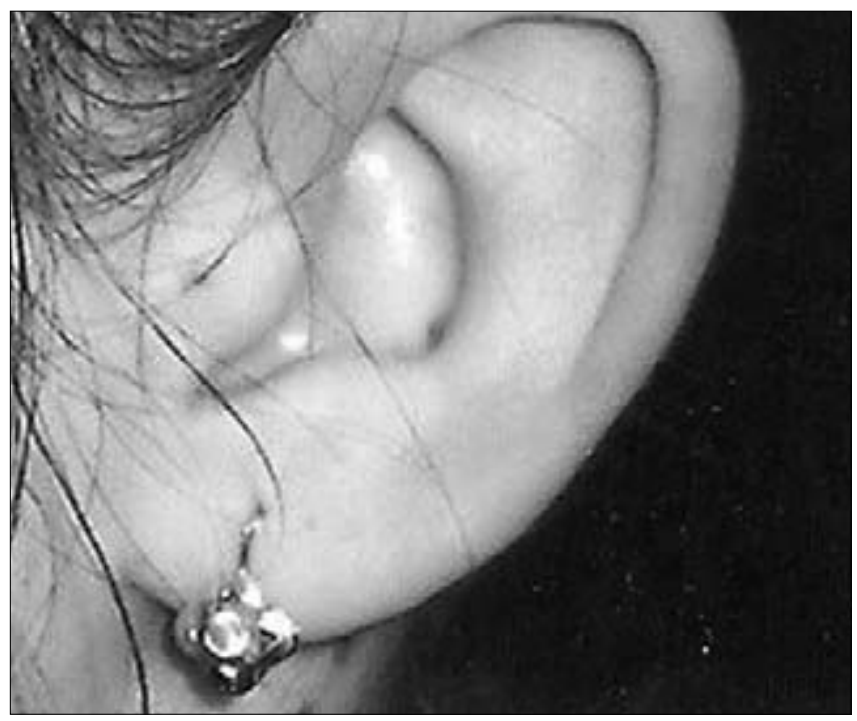

Figure 2.

External ear grossly formed with hypoplastic lobule

The patient was treated with Androcur $(75 \mathrm{mg} /$ day $)$ and Suprefact (3 inhalations/day).

Every 6 months, the patient was followed up for weight and height, LH, FSH, estradiol, evolution of sexual signs, and bone age. A good response to the treatment was observed, with height at the $75^{\circ}-90^{\circ}$ percentile (7 years of age). On echography at 6 years of age, the right and left ovary appeared of adult $(3 \mathrm{cc}$, volume).

\section{Discussion}

The patient was affected by OAVS 1,2 with hemifacial microsomia, microphthalmia, macrostomia, right palpebral ptosis, malformed ear, scoliosis, short stature, velopharyngeal insufficiency, thumb abnormalities, hydrocephalus, and precocious puberty 3,4,5,6,7.

The minimal symptoms for the diagnosis of OAVS include at least two of these features: hemifacial microsomia, otic hypoplasia, vertebral abnormalities, epibulbar dermoid and/or upper eye lid coloboma (the two last symptoms typical of Goldenhar syndrome ${ }^{8}$ ). Other features may be associated: palpebral abnormalities or ptosis, hypoplasia of internal or middle ear canal 9,10, macrostomia, platybasia ${ }^{11}$, plagiocephaly, cheiloschisis, cheilognathopalatoschisis ${ }^{12}$, scoliosis ${ }^{13}$, limb, cardiac, urogenital malformations ${ }^{14}$, clinodactyly, flexion of fifth fingers, abnormalities of thumb, velo-pharyngeal insufficiency ${ }^{15}$, short stature. OAVS includes Goldenhar syndrome ${ }^{16}$, characterized by the association of hemifacial microsomia, microtia, skeletal abnormalities, and dermoid. To our knowledge, precocious puberty in OAVS was never reported.

OAVS is considered a malformative syndrome due to a defect of blastogenesis, an embryonic stage spanning from fertilization of ovum to day 28 in humans in which trilaminar embryo develops and neural crest cells develop and migrate ${ }^{17}$.

OAVS is now considered a first and second branchial arch malfor- 

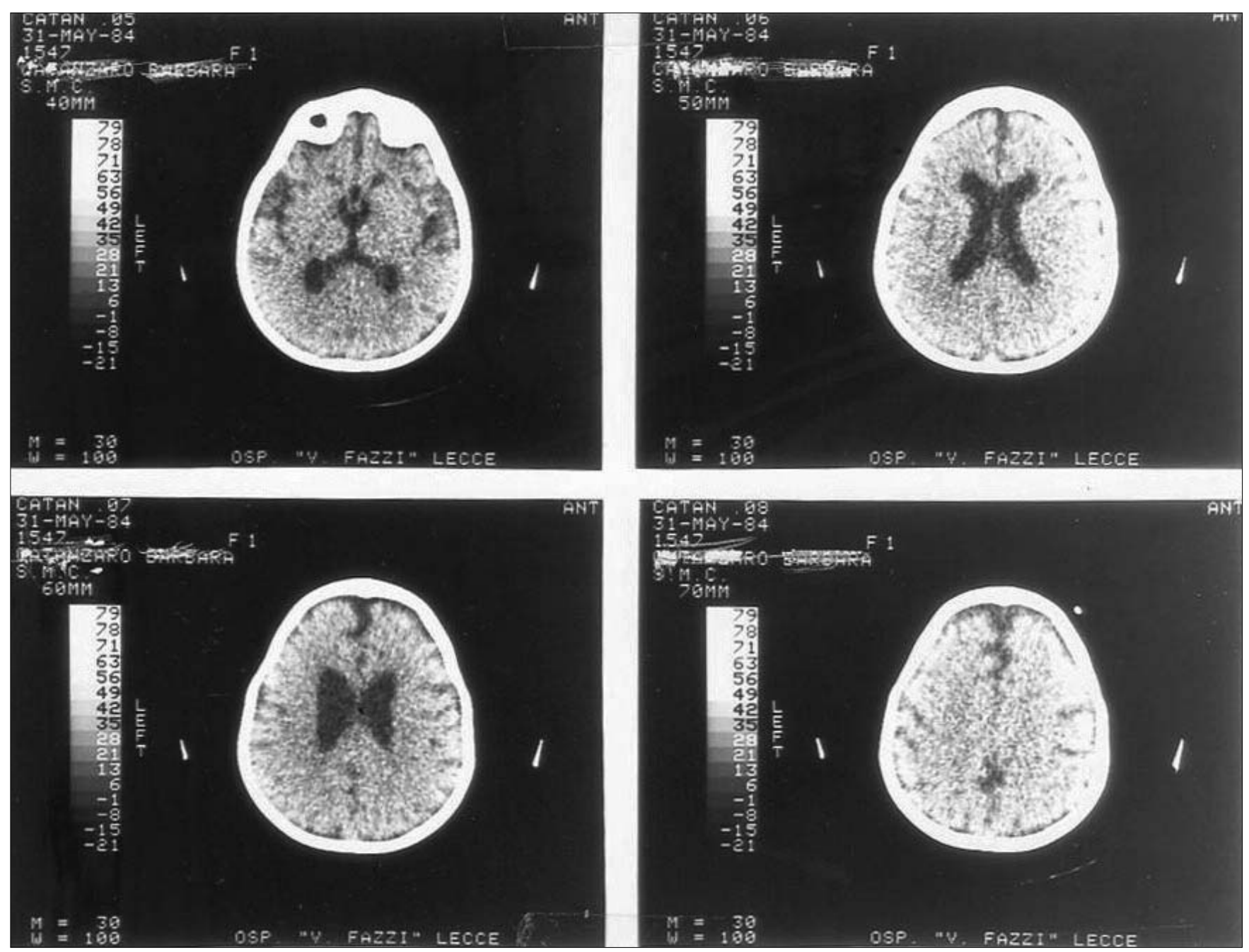

Figure 3.

Brain CT: enalarged cerebral ventricles and subarachnoid spaces with slight cerebral atrophy, hydrocephalus.

mative syndrome ${ }^{2}$ mainly due to abnormalities of neural crest cells (NCC) migration or interaction with other tissues 18,19 .

In normal subjects, the NCC induce the development of bone, cartilage, peripheral nerves, and vascular structures of the face, via formation of transitory primordial structures (5 branchial arches). Prosencephalic NCC contribute to fronto-nasal-philtrum structures and exert a critical effect on the development of prosencephalon differentiation into telencephalon and diencephalon ${ }^{18,19}$. Mesencephalic NCC contribute to the development of maxilla and jaw (in part) and of midbrain ${ }^{19}$. Rhombencephalic NCC are responsible of the development of mandibular structures ${ }^{19}$.

The first structures of the skull (desmocranium) originate from NCC at about 4 weeks of embryonal life 18 and induce chondrocranium: their developments is concomitant with that of brain and foregut.

The formation of cranial and facial bone and cartilage is strictly connected with the hypothalamic-hypophyseal axis. The oral ectoderm originates the anterior pituitary gland with the initial forma-

Table

\begin{tabular}{|c|c|c|c|c|c|c|c|c|}
\hline Age & Bone age & Height & Weight & Breast & LH & FSH & Estradiol & $17 \mathrm{KS}$ \\
\hline Years & Years & $\mathrm{Cm}$ & $\mathrm{Kg}$ & & $\mathrm{mlU} / \mathrm{ml}$ & $\mathrm{mlU} / \mathrm{ml}$ & $\mathrm{Pg} / \mathrm{ml}$ & mg/day \\
\hline 4,6 & $8-9$ & 106.5 & 21.8 & + & 7.9 & 10.6 & $14-17.3$ & $0.56-2.7$ \\
\hline & & & & & $\begin{array}{l}\text { After GnRH } \\
20 \mathrm{~min}=75.9 \\
60 \mathrm{~min}=47.4 \\
90 \mathrm{~min}=34.6\end{array}$ & $\begin{array}{l}20.7 \\
24 \\
21.9\end{array}$ & & \\
\hline
\end{tabular}


tion of a rudimentary Rathke pouch without mesoderm between the pouch and the floor of the diencephalon, followed by the formation of a definitive pouch and of the posterior hypophyseal lobe, the invasion of NCC and of the mesenchyme, and the separation of the brain and the oral cavity by mesenchymal tissue ${ }^{20}$. Under the inductive action of cephalic NCC, migrated to the pre-chordal skull base, the overlying neural tube is transformed into prosencephalion and then into diencephalons and telencephalon ${ }^{18}$. Cephalic NCC control Fgf expression in the anterior neural ridge (i.e. the prosencephalic organizer) and the development of pre-otic brain and of diencephalon and mesencephalon. However they also control the Fgf in branchial arch ectoderm 21,22 and the development of craniofacial structures. This condition explains why hypothalamic pituitary dysfunction is frequently associated with a variety of prechordal malformations of the skull base.

OAVS is mainly a first and second arch malformative syndrome, but skull base ${ }^{18}$ and CNS malformations ${ }^{23}$ are frequently associated. In our case, hypothalamic-pituitary disfunction was also associated and manifested as precocious puberty. In an abnormal NCC migration to the future pre-chordal area which will be the skull base region, the overlying diencephalic neural tube may not present an appropriate induction, with consequent abnormality of the hypothalamic-pituitary axis ${ }^{18}$. In our case we can hypothesize that skull base and face malformations are associated with diencephalic-pituitary functional alterations leading to precocious puberty.

In OAVS, the malformations of the CNS are frequent ${ }^{23}$. Hydrocephalus has been reported in $38.1 \%$ of pregnancies with OAVS children 24 and in some subjects of pediatric ages 25,26,27,28. Low tension hydrocephalus was reported by Michaud and Sheridan 29 but, to our knowledge, hydrocephalus has never been found associated with precocious puberty in OAVS.

Onset of puberty is controlled by two events: awakening or release from inhibition of neurons in the medial hypopthalamus, which secrete $\mathrm{GnRH}$, and a concomitant decrease in hypothalamic-pituitary sensitivity to the negative feedback of steroids secreted by gonads. These changes are associated with an increase in pulse frequency and in LH and FSH concentration (to a lesser extent) ${ }^{30}$. In most istances, precocious puberty is considered idiopathic, mainly in girls, but in some cases it is due to hypothalamic hamartoma ${ }^{3}$ or to hydrocephalus 4 .

In 15/16 subjects with non-tumoral shunted hydrocephalus without raised intracranial pressure, Brauner et al ascribed the presence of precocious puberty to a central cause 5 Precocious puberty due to hydrocephalus is more frequent in females and is not early nor commonly associated with GH deficiency 5 .

In our case, we hypothesize a malformative hydrocephalus that may cause physical perturbation of inhibitory pathways 6 in the hypothalamus. Alternatively, alterations of the hypothalamus due to compression of hydrocephalus or to functional abnormality not demonstrated by TC or MRI may have impaired the inhibitory gonadotropin secretory cells, causing precocious puberty 7 .

In agreement with this hypothesis, precocious puberty is well controlled by LHRH analogs, which suppress gonadotropin secretion 31
, or by long acting LHRH analogs which normalize basal serum peak of LH and FSH on LH-RH stimulation test ${ }^{6,7}$. Similar positive results were observed, in our case, after therapy. It was reported that non-random left vs. right laterality of malformation in paired structures may be present in malformed subjects ${ }^{32}$ and was present in our OAVS patient.

In our case, nasal speech and swallowing difficulties commonly reported in OAVS were present. Shpritzen et al. ${ }^{15}$ observed that, in OAVS, gaps were laterally located in the pharynx on the same side as the facial microsomia. They ascribed hypernasal speech and swallowing difficulties to a unilateral paresis of the velar and pharyngeal muscles necessary for velo-pharyngeal closure, due to unilateral hypoplasia of constrictors and other pharyngeal muscles, with asymmetry of pharyngeal movements and consequent speech and swallowing abnormalities.

These reports support the hypothesis that the malformative complex in OAVS may involve other structures in addition to the face ${ }^{1}$ and that OAVS is due to abnormal right-left body axis development during blastogenesis ${ }^{17}$. An abnormality in left-right axis may also explain the facial and ovary maturation asymmetry present in our patient. The aetiology of OAVS, as that of Goldenhar syndrome, is heterogeneous. This syndrome was observed with high frequency in children born to diabetic mothers, and to mother who used thalidomide, cocaine, or retinoids, during pregnancy ${ }^{33}$. In some families, a dominant or recessive autosomal inheritance was reported, while in others OAVS was sporadic ${ }^{14}$. Various chromosome rearrangements or deletions were reported in associations with OAVS, (chromosomes $1,5,6,8,18,22) 23$. We previously reported a case of OAVS associatd with a microdeletion of chromosome 1, i.e. 1:46, $\mathrm{xx}$ del (I) (q 21.1) 23 .

In patients with 1q deletion, this syndrome was correlated with deletion extent ${ }^{34}$. However, chromosome mutations do not seem to be a relevant cause of OAVS ${ }^{14}$. No chromosome abnormality was reported in the present case. The molecular basis of OAVS is still unclear ${ }^{14}$ because, in many cases, gene mutation was not reported. At present, OAVS may be considered a contiguous gene disorder with smaller deletions in patients mildly affected and larger deletions in severely affected ones ${ }^{14}$ and this syndrome may be considered a neurocristopathy ${ }^{23}$. In cranio-facial and central nervous system development, many neural crest cell related genes are thought to play an important role ${ }^{19}$. Cells of neural fold epithelium share the same expression as conventional neural crest cell markers (e.g. Snails gene family members ${ }^{35}$, Fox D3, Msx) ${ }^{36}$. Msx genes expressed in cephalic NCC ${ }^{34}$ are effectors of cells of the neural fold epithelium of Bmp, Wnt, Fgf pathways, which have a well determined role in NCC development. Msx genes have a critical role in first branchial arch differentiation ${ }^{13}$.

Experimentally, hemizygous mice with mutated Msx gene exhibited hypoplastic first pharyngeal arch, due to delayed migration and/or increased apoptosis of NCC. Msx homeobox genes have a parallel action to that of Dlx 5 and are downstream to it in jaw development, Dlx is stronger expressed in the first arch in animals and regulates mandibular prominence. Partial loss of function of 
Msx gene due to mutations are considered important in familial cases of OAVS 13 .

Dlx and Hox genes, induce maxillary and mandibular bone development. Hox gene expression is lacking in the paraxial mesoderm (which gives rise to cranio-facial muscles) and is absent in NCC of the first pharyngeal arch, which generate many skull bones (dentary, maxillary, squamosal, tympanic, malleus, incus bones) and the Meckel cartilage 36 but skeleton development requires foregut endoderm cells ${ }^{37}$. Shh gene in animals, expressed in pre-chordal mesoderm and in the midline structures underlying the Neural Plate ${ }^{38}$, induces the development of the ventral prosencephalon, the dorsoventral disposition of the prosencephalic structures (i.e. cerebral cortex, basal nuclei, septum, thalamus, hypothalamus ${ }^{39,40}$ ), the separation of the two eyes, the development of some NCC derived facial bones ${ }^{39}$, and the formation of ventral forebrain i.e. optic vessels, optic recess, hypothalamus ${ }^{18}$. Pax 6 plays a role in forming the hypophyseal cell type ${ }^{41}$. Therefore it is possible that in our patient multiple gene mutations possibly contiguous may have caused the OAVS, via malregutation of NCC development or migration, or via abnormal integration of NCC with mesodermal structures present in branchial arches and may have caused precocious puberty via hypothalamic-pituitary axis functional malregulation. Other studies have suggested a role of the Goosecoid gene (in chromosome 14q32) in hemifacial microsomia development 42 and of BAPXI gene ${ }^{43}$.

In OAVS development further studies could indicate the abnormal genetic ground present in our patient, but NCC pathology seems to play a major role in OAVS.

\section{References}

1 Gorlin RJ, Jue KL, Jacobsen U, Goldschmidt E. Oculoauriculovertebral dysplasia. J Pediat 1963; 63: 991-9.

2 Grabb WC. The first and second branchial arch syndrome. Plast Reconstr Surg 1965; 36: 485-508.

3 Cacciari E, Frejaville E, Cicognani A, Pirazzoli P, Frank G, Balsamo A et al. How many cases of true precocious puberty in girls are idiopathic? J Pediat 1983; 56: 357-360.

4 Brauner R, Rappaport R, Nicod C, Malandry P, Thibaud I et al. Pubertés précoces vraies au cours de l'hydrocéphalie non tumorale. Arch Fr Pediat 1987; 44: $433-436$

5 Brauner R, Pierre-Kahn A, Nemedy-Sandor E, Rappaport R, Hirsch JF. Pubertés précoces par kyste arachnoidien suprasellaire. Arch Fr Pediat 1987; 44: 489-493.

6 Booth TN, Timmons C, Shapiro K, Rollins NK. Pre- and post-natal MR imaging of hypothalamic hamartomas associated with arachnoid cyst. AJNR 2004; 25: 1283-1285.

Arita K, Ikawa F, Kurisu K, Sumida M, Harada K et al. The relationship between MRI findings and clinical manifestations of hypothalamic hamartoma. J Neurosurg 1999; 91: 212-220.

8 Kumar A, Friedman JM, Taylor GP, Patterson MWH. Pattern of cardial malformation syndrome in oculoauriculovertebral spectrum. Am J Med Gen 1993; 146: 423-6.
9 Stromland K, Miller M, Sjogreen C, Johansson M, Ekman BM, Billstedt E. OAV spectrum. Am J Med Gen 2007; 143A: 1317-25.

10 Bisdas S, Lenarz M, Lenarz T, Becker H. Inner ear abnormalities in patients with Goldenhar's syndrome. Otology and Neurology 2005; 26: 398404.

11 Michaud C, Sheridan S. Goldenhar's syndrome associated with cranial and neurological malformations. Canad J Ophthalmol 1974; 9: 347-50.

12 Nijhawan N, Morad Y, Seigel-Bartelt J, Levin AV. Caruncle abnormalities in the oculoauriculovertebral spectrum. Amer J Med Genet 2002; 113: 3205.

13 Stoll C, Viville B, Treisser A, Gasser B. A family with dominant oculoauriculovertebral spectrum. Amer J Med Genet 1998; 78: 345-9.

14 Tasse C, Mayewski F, Bohringer S, Fisher S, Ludecke HJ, Gillessen-Kaesbach G. A family with dominant oculoauriculovertebral spectrum. Clin Dysmorphology 2007; 16: 1-7.

15 Shprintzen RJ, Croft CB, Berkman MD, Rakoff SLJ. Velopharyngeal insufficiency in the facioauriculo vertebral malformation complex Cleft Palate. J 1980; 17: 132-137.

16 Goldenhar M. Association malformatives de l'oeil et de l'oreille en particulier le syndrome dermoide epibulbaire-appendices auriculaire-fistula auris congenita et ses relations avec la dysostose mandibulofaciale. J Genet Hum 1952; $1: 243-82$.

17 Opitz JM, Zanni G, Reynolds JF, Gilbert-Barness E. Defects of blastogenesis. Amer J Med Genet 2002; 115: 269-80.

18 Blustajn J, Netchine J, Fredy D, Bakouche P, Piekarski JD, Meder JF. Dysgenesis of the internal carotid artery associated with transphenoidal encephalocele: a neural crest syndrome? AJ NR 1999; 20: 1154-57.

19 Le Douarin NM, Kalcheim C. The neural crest. Cambridge Univ. Press New York 1999.

20 Dattani M, Preece M. Growth hormone deficiency and related disorders: insights into causative, diagnosis and treatment. Lancet 2004; 363: $1977-$ 1983.

21 Creuzet S, Schuler B, Couly G, Le Douarin NM. Reciprocal relationships between Fgf8 and neural crest cells in facial and forebrain development. PNAS 2004; 101: 4843-4847.

22 Creuzet S, Martinez S, Le Douarin NM. The cefalic neural crest exerts a critical effect on forebrain and midbrain development. PNAS 2006; 103: 14033-14038.

23 Berio A, Mangiante G, Oliaro E, Piazzi A. Oculoauriculovertebral syndrome with large cerebral cyst: affinity to holoprosencephaly. Min Pediat 2012; 64: 549-554.

24 Castori M, Brancati F, Rinaldi R, Adami L, Minganelli R et al. Antenatal presentation of the oculoauriculovertebral spectrum. Amer J Med Genetics 2006; 140A: 1573-79.

25 Aleksic S, Budzilovich G, Greco MA, McCarthy J, Reuben R, Margolis S. Intracranial lipomas, hydrocephalus and other central nervous system anomalies in oculoauriculovertebral dysplasia (Goldenhar-Gorlin syndrome). Childs Brain 1984; 11: 285-97.

26 Wilson GN. Cranial defects in Goldenhar syndrome. Amer J Med Genet 1983; 14: 435-43.

27 Murphy MJ, Risk W, Van Gilder J. Intracranial dermoid cyst in Goldenhar's syndrome. J Neurosurg 1980; 53: 408-11.

28 Zelante L, Gasparini I, Castriota-Scanderbeg A, Dimitri L, Criconia A, Gorlin RJ. Goldenhar complex. Amer J Med Genet 1997; 69: 418-21.

29 Michaud C, Sheridan S. Goldenhar's syndrome associated with cranial and neurological malformations. Canadian J Opthalmol 1974; 9: 347-350. 
30 Lancet. (The) Precocious puberty (Editorial) 1991; 337: 1194-95.

31 Comite F, Peskovitz DH, Rieth KG et al. Luteinizing hormone-releasing hormone analog treatment of boys with hypothalamic hamartoma and true precocious puberty. J Clin Endocrinol Metab 1984; 59: 888-892.

32 Schnall BS, Smith DW. Nonrandom laterality of malformations in paired structures. J Pediat 1974; 85: 509-511.

33 Wang R, Martinez-Frias ML, Graham JM. Infants of diabetic mothers are at increased risk for the oculoauriculovertebral sequence: a case based and casecontrol approach. J Pediat 2002; 141: 611-617.

34 Hill AD, Chang B, Hill RS, GArraway LK, Bodell A et al. A 2 MB critical region implicated in the microcephaly associated with terminal 1q deletion syndrome. J Med Genet 2007; 143A: 1962-8.

35 Gammill LS, Bronner-Fraser M. Neural crest specification: migrating into genomics. Nature Rev-Neuroscience 2003; 4: 795-805.

36 Mark M, Rijli FM, Chambon P. Homeobox genes in embryogenesis and pathogenesis. Pediatric Res 1997; 41: 421-429.

37 Couly G, Creuzet, Bonnaceur S, Vincent C, Le Douarin NM. Interactions between Hox-negative cephalic neural crest cells and the foregut endo- derm in patterning the facial skeleton in the vertebrate head. Development 2002; 129: 1061-1073.

38 Krumlauf R. Hox genes and pattern formation in the branchial region of the vertebrate head. Trends Genet 1993; 9: 106-112.

39 Jeong J, Mao J, Tenzen T, Kottman AH, Mc Mahon A. Hedgehog signaling in the neural crest cells regulates the patterning and growth of facial primordial. Genes and Development 2004; 18: 937-951.

40 Goodman FR. Congenital abnormalities of body patterning: embryology revisited. Lancet 2003; 362: 651-662.

${ }^{41}$ Kioussi C, O’Connell S, StOnge L, Treier M, Gleiberman AS, Gruss P, Rosenfeld MG. PAx 6 is essential for establishing ventral-dorsal cells boundaries in pituitary gland development. PNAS 1999; 96: 14.378-14.382.

42 Kelberman D, TysonJ, Chandler DC, Mc Inerney AM, Sle J, Albert D et al. Hemifacial microsomia: progress in understanding the genetic basis of a complex malformation syndrome. Hum Genet 2001; 109: 638-45.

43 Fisher S, Ludecke HJ, Wieezorek D, Bohringer S, Gillesen-Kaesback GE, Horsthemke B. Histone acetylation dependent allelic expression imbalance of BAPXI in patients with OAVS. Hum Mol Gen 2006; 15: 581-587. 